\title{
Development of a Saudi Palliative Care Essential Medication List (EML)
}

\author{
Sami Ayed Alshammary ${ }^{*}$, Igbal Abdelati Mahgoub ${ }^{2}$, Waleed Alshehri ${ }^{3}$, Yacoub Abuzied ${ }^{4}$ and \\ Abdullah Al Tamimi ${ }^{4}$ \\ ${ }^{1}$ Palliative Care Unit, Comprehensive Cancer Centre, King Fahad Medical City, Riyadh and Center for Postgraduate Studies in \\ Family Medicine, Ministry of Health, Saudi Arabia
}

${ }^{2}$ Albait Home Care for Health Services, Saudi Arabia

${ }^{3}$ Clinical Pharmacy Department, King Fahad Medical City Riyadh, Saudi Arabia

${ }^{4}$ Department of Nursing, King Fahad Medical City, Saudi Arabia

*Corresponding author: Sami Ayed Alshammary, Palliative Care Unit, Comprehensive Cancer Centre, King Fahad Medical City, Riyadh and Center for Postgraduate Studies in Family Medicine, Ministry of Health, Riyadh, Saudi Arabia

\section{ARTICLE INFO}

Received: 崫 May 05, 2021

Published: 巒 May 20, 2021

Citation: Sami Ayed Alshammary, Igbal Abdelati Mahgoub, Waleed Alshehri, Yacoub Abuzied, Abdullah Al Tamimi. Development of a Saudi Palliative Care Essential Medication List (EML). Biomed J Sci \& Tech Res 35(5)-2021. BJSTR. MS.ID.005778.

Keywords: Essential; Medication; List; Palliative; Care

Abbreviations: EML: Essential Saudi Palliative Medication List; WHO: World Health Organization; PC: Palliative Care; SPSS: Statistical Package for the Social Sciences; IR: Immediate Release; SR: Sustained Release; SHC: Saudi Health Council; KSA: Kingdom of Saudi Arabia; MOH: Ministry of Health

\section{ABSTRACT}

Background: In response to the request of the Saudi Health Council, an expert palliative multi-disciplinary central committee was created to develop a model of the essential Saudi palliative medication list (EML), to be updated every 2 years, based on the World Health Organization (WHO) criteria for EML.

Objectives: Our aim was to explore the degree of consensus among physicians involved in palliative care (PC) regarding appropriate pharmacological treatment for common symptoms of palliative patients with cancer and to thus develop a national medication list of essential medicines for PC based on expert opinion. This list will serve as a key for future decision making in clinical practice.

Methods: We conducted a descriptive cross-sectional study of all consultants from July 2020 to August 2020. A structured questionnaire was used to collect the data, which were analyzed using Statistical Package for the Social Sciences (SPSS) version 25.

Results: The top palliative consultant experts in the Kingdom of Saudi Arabia participated in the study, with a high level of consensus among the experts. More than 60 medications were included in the review. The survey influenced the PC medication list following consensus. The preference for a medication was grouped into three categories - mandatory, necessary, and optional-based on administration frequency and the specified categories. The "mandatory" medications such as baclofen tablets, loperamide, ibuprofen tablets, midazolam injections, Tylenol III and fentanyl injections, morphine injections, morphine (IR) syrup, and morphine (SR) tablets were considered. The "necessary" medications such as modafinil tablets, morphine (SR) 60 mg, megestrol, and prednisone were considered. The "optional" medications included the following: fentanyl $500 \mathrm{mcg}$ injections, hydrocortisone cream, and atropine eye drops.

Conclusions: The drugs prescribed and reported in this survey can be incorporated with the WHO EML, which in turn can lead to a constructive change in local drug policies and provide a basis for the minimum standard of care for PC institutions. 


\section{Introduction}

Palliative care (PC) is an approach that enhances the quality of life of patients (adults and children) and their families who are dealing with complications related to life-threatening illnesses [1]. Such care prevents and relieves discomfort by detecting, assessing, and treating pain and other symptoms as early as possible, including medical, psychosocial, and moral issues. In June 2018, the Saudi Palliative Care National Clinical Guidelines for Oncology were established. These guidelines were developed to include proof- and consensus-based recommendations for best practice advice for a variety of common clinical problems in PC. They also serve as a comprehensive roadmap for healthcare practitioners to standardize practice in order to ensure the highest level of care for PC patients and their families, which supports both generalist and specialty PC providers [2]. Since the World Health Organization (WHO) first introduced the definition of essential drugs, it has become an important component of national health-care policies and activities. The importance of vital drugs combined with healthcare programs is being strengthened as health institutions work for universal health coverage. This incorporation enables prescribing doctors to provide treatment for patients without jeopardizing the patient's care due to the consequences of their therapy and financial condition, so patients should be able to access the clinical benefits they need without encountering insurance problems [2,3]. Currently, certain PC drugs are listed in the related portions of the WHO Expert Committee Model List based on their medicinal application, with analgesics being a particular example $[4]$.

Based on expert views, PC organizations and agencies have identified or created lists of important medicines for PC [5-7]. The WHO has created a Model List of Essential Medicines (EML), which is revised every two years and is dependent on each medicine's reliability, efficacy, and cost-effectiveness [8,9]. In response to the Saudi Health Council (SHC) request, an expert palliative multidisciplinary central committee was formulated to develop a model of Saudi essential palliative medication lists (EML) to be updated every 2 years, based on the WHO criteria of EML (the safety, efficacy and cost-effectiveness of each medicine listed) [9]. The definition and EML were suggested as expert recommendations to the Kingdom of Saudi Arabia (KSA) in order to establish national PC critical medicine policies and lists. The SHC has created recommendations with the aim of assisting all healthcare professionals interested in the treatment of palliative patients in the implementation of national Saudi critical medicine policies and lists for PC. Essential drugs are those that meet the majority of the population's healthcare needs $[10,11]$. They are chosen based on their importance to public health, proof of efficacy and safety, and comparative cost-effectiveness [9-11]. It is recommended that essential drugs be made available at all times within the framework of working health institutions, in sufficient quantities, suitable dosage types, with assured quality and adequate detail, and at a price that individuals and the community can afford [12]. The EML can be used as a starting point for future changes, such as the inclusion or elimination of old or new medications [13]. Policymakers in national health care systems will use the EML to pick available drugs on the market that will fulfill their country's healthcare needs while being cost-effective $[13,14]$. Our problem where in most palliative patients do not have access to the necessary drugs, despite evidence of drug efficacy, to alleviate their most common symptoms. Our aim was therefore to explore the degree of consensus among physicians working in specialist PC regarding appropriate pharmacological treatment for common symptoms for palliative patients with cancer, and to develop a national list of essential medicines for PC, based on expert opinion, that will serve as a key aid for decision making in future practice.

\section{Methodology \\ Study Design/Setting}

From July to August 2020, we performed a descriptive crosssectional analysis of all consultants. For the current study, a standardized questionnaire was used, with the emphasis on the particular frequency of treatment used by the WHO EML. We did, however, gather data through a monkey survey.

\section{Study Population}

Our population included PC consultants who were selected based on their expertise. Demographics, career history as a PC physician, and a multidisciplinary team were among the information gathered.

\section{Data Source}

The central committee distributed the surveys to top PC experts in the KSA. Experts were defined as physicians currently working in specialist PC units, with at least 2 years of practice as a PC physician. The selection criteria were as follows: senior PC consultant, academic or research interest, and geographical distribution of different healthcare providers. All participants were recruited from different KSA regions in the PC units through each PC unit's representative. Representatives were asked to contact experts. The selected physicians from different PC units received an e-mail invitation to participate in the survey to develop the final list by listing their first and second choices of generic drugs. The response rate was $70 \%$. In the second ad hoc group discussion, the most common symptoms in PC were identified, and their medications were included in the list of essential medicines for palliative care. The survey results changed the PC medication list draft according to the majority vote. While this list was not based on scientific evidence, but rather on expert opinion, the 
expert committee finalized the lists to include the classification of "mandatory," "essential," and "optional” PC sections of the EML.

\section{Variable Definitions}

The questionnaire was divided into two sections. The first section included demographic data such as age, sex, job position, organization, and years of experience in PC. In the second section, experts had to classify the palliative medications into three categories: mandatory, necessary, and optional.

\section{Statistical Analysis}

The data were analyzed using Statistical Package for the Social Sciences (SPSS) version 25. Descriptive data were reported as frequencies and percentages to examine the distribution of study variables among the three categories.

\section{Ethical Considerations}

The Institutional Review Board of King Fahad Medical City in Riyadh, Saudi Arabia, reviewed and approved this study.

\section{Results}

Total of 12 Consultants participated in the study, $72.7 \%$ of whom were female and $18.2 \%$ of whom were male. Working Table 1: Palliative Care Medication Survey Result. experience ranged from less than five years to more than 11 years. Of the participants, $36.4 \%$ had 6 to 10 years of experience. The percentage of participants with less than 5 years and more than 11 years of experience was $27.3 \%$ in each group. Participants were from the Ministry of Defense Hospitals (9.1\%), Ministry of Health Hospitals (72.7\%), and Ministry of the Interior Hospitals (9.1\%) (Table 1). Preferences for medication were grouped into three categories: mandatory, necessary, and optional. The frequency of administration of each medication was reviewed based on the specified categories. Ninety percent of the participants reported that baclofen 10mg tablets were "Mandatory," followed by loperamide $2 \mathrm{mg}$ capsules, ibuprofen $400 \mathrm{mg}$ tablets, and midazolam $15 \mathrm{mg} / 3 \mathrm{~mL}$ injections. Tylenol III (acetaminophen 300mg \& codeine $30 \mathrm{mg}$ ) and fentanyl $100 \mathrm{mcg}$ injections were considered "Mandatory" by $80 \%$ of the participants, followed by morphine $10 \mathrm{mg} / \mathrm{mL}$ injections, morphine (IR) $10 \mathrm{mg} / 5 \mathrm{~mL}$ syrup, morphine (SR) $10 \mathrm{mg}$ tablets, morphine (SR) $30 \mathrm{mg}$ tablets, tramadol $100 \mathrm{mg}$ injections, tramadol $100 \mathrm{mg}$ injections, lorazepam $1 \mathrm{mg}$ tablets, dexamethasone $8 \mathrm{mg} / 2 \mathrm{~mL}$ injections, dexamethasone $8 \mathrm{mg}$ tablets, haloperidol $5 \mathrm{mg} / \mathrm{mL}$ injections, octreotide $100 \mathrm{mcg} / \mathrm{mL}$ injections, hyoscine butyl bromide $20 \mathrm{mg} / \mathrm{mL}$ injections, and more, as shown in Table 2.

\begin{tabular}{|c|c|c|c|c|c|c|}
\hline \multirow{2}{*}{ Variables } & \multicolumn{2}{|c|}{ Mandatory } & \multicolumn{2}{|c|}{ Necessary } & \multicolumn{2}{|c|}{ Optional } \\
\hline & (n) & $(\%)$ & (n) & (\%) & (n) & (\%) \\
\hline Morphine $10 \mathrm{mg} / \mathrm{ml}$ injection & 7 & 70 & 3 & 30 & 0 & 0 \\
\hline Morphine (IR) 10mg tablet & 6 & 60 & 4 & 40 & 0 & 0 \\
\hline Morphine (IR) $10 \mathrm{mg} / 5 \mathrm{ml}$ syrup & 7 & 70 & 3 & 30 & 0 & 0 \\
\hline Morphine (SR) $10 \mathrm{mg}$ tablet & 7 & 70 & 3 & 30 & 0 & 0 \\
\hline Morphine (SR) 30mg tablet & 7 & 70 & 3 & 30 & 0 & 0 \\
\hline Morphine (SR) 60mg tablet & 3 & 30 & 5 & 50 & 2 & 20 \\
\hline Fentanyl 100 mcg injection & 8 & 80 & 2 & 20 & 0 & 0 \\
\hline Fentanyl 500 mcg injection & 2 & 20 & 3 & 30 & 5 & 50 \\
\hline Fentanyl 25 mcg patch & 6 & 60 & 4 & 40 & 0 & 0 \\
\hline Fentanyl 50 mcg patch & 5 & 50 & 3 & 30 & 2 & 20 \\
\hline Fentanyl 100 mcg sublingual tablet & 4 & 40 & 3 & 30 & 3 & 30 \\
\hline Codeine phosphate $30 \mathrm{mg}$ tablet & 6 & 60 & 1 & 10 & 3 & 30 \\
\hline Tylenol III (Acetaminophen 300mg \&amp; & 8 & 80 & 1 & 10 & 1 & 10 \\
\hline Tramadol 100mg injection & 7 & 70 & 0 & 0 & 3 & 30 \\
\hline Tramadol 50mg tablet & 5 & 50 & 3 & 30 & 2 & 20 \\
\hline Tramadol 100mg tablet & 4 & 40 & 3 & 30 & 3 & 30 \\
\hline Naloxone $0.4 \mathrm{mg} / \mathrm{ml}$ injection & 7 & 70 & 3 & 30 & 0 & 0 \\
\hline Acetaminophen $500 \mathrm{mg}$ tablet & 8 & 80 & 2 & 20 & 0 & 0 \\
\hline Ibuprofen $400 \mathrm{mg}$ tablet & 8 & 80 & 2 & 20 & 0 & 0 \\
\hline Midazolam $15 \mathrm{mg} / 3 \mathrm{ml}$ injection & 8 & 80 & 2 & 20 & 0 & 0 \\
\hline Lorazepam $1 \mathrm{mg}$ tablet & 7 & 70 & 3 & 30 & 0 & 0 \\
\hline Atropine eye drops $1 \%$ & 4 & 40 & 2 & 20 & 4 & 40 \\
\hline Benztropine $2 \mathrm{mg} / 2 \mathrm{ml}$ injection & 6 & 60 & 2 & 20 & 2 & 20 \\
\hline Dexamethasone $8 \mathrm{mg} / 2 \mathrm{ml}$ injection & 7 & 70 & 2 & 20 & 1 & 10 \\
\hline
\end{tabular}




\begin{tabular}{|c|c|c|c|c|c|c|}
\hline Dexamethasone 8mg tablet & 7 & 70 & 2 & 20 & 1 & 10 \\
\hline Prednisone $10 \mathrm{mg}$ tablet & 3 & 30 & 4 & 40 & 3 & 30 \\
\hline Hydrocortisone cream & 4 & 40 & 1 & 10 & 5 & 50 \\
\hline Haloperidol 5mg/ml injection & 7 & 70 & 3 & 30 & 0 & 0 \\
\hline Octreotide $100 \mathrm{mcg} / \mathrm{ml}$ injection & 7 & 70 & 3 & 30 & 0 & 0 \\
\hline $\begin{array}{l}\text { Hyoscine butyl bromide } 20 \mathrm{mg} / 1 \mathrm{ml} \\
\text { injection }\end{array}$ & 7 & 70 & 3 & 30 & 0 & 0 \\
\hline Glycopyrronium $200 \mathrm{mcg} / \mathrm{ml}$ injection & 7 & 70 & 3 & 30 & 0 & 0 \\
\hline Metoclopramide $10 \mathrm{mg} / 2 \mathrm{ml}$ injection & 7 & 70 & 3 & 30 & 0 & 0 \\
\hline Metoclopramide $10 \mathrm{mg}$ tablet & 7 & 70 & 3 & 30 & 0 & 0 \\
\hline Diphenhydramine $25 \mathrm{mg}$ tablet & 6 & 60 & 4 & 40 & 0 & 0 \\
\hline Diphenhydramine $25 \mathrm{mg}$ injection & 7 & 70 & 3 & 30 & 0 & 0 \\
\hline Bisacodyl 5mg tablet & 7 & 70 & 3 & 30 & 0 & 0 \\
\hline Bisacodyl $10 \mathrm{mg}$ suppositories & 7 & 70 & 3 & 30 & 0 & 0 \\
\hline Docusate sodium $100 \mathrm{mg}$ capsules & 6 & 60 & 3 & 30 & 1 & 10 \\
\hline Senna 8mg tablet & 7 & 70 & 3 & 30 & 0 & 0 \\
\hline Lactulose solution & 8 & 80 & 2 & 20 & 0 & 0 \\
\hline Glycerine suppositories & 7 & 70 & 3 & 30 & 0 & 0 \\
\hline Fleet enema & 7 & 70 & 2 & 20 & 1 & 10 \\
\hline Loperamide $2 \mathrm{mg}$ capsules & 8 & 80 & 1 & 10 & 1 & 10 \\
\hline Nystatin 100,000 units/ml oral liquid & 7 & 70 & 3 & 30 & 0 & 0 \\
\hline Pregabalin $50 \mathrm{mg}$ and $150 \mathrm{mg}$ capsules & 7 & 70 & 3 & 30 & 0 & 0 \\
\hline Gabapentin $300 \mathrm{mg}$ and $800 \mathrm{mg}$ capsules & 5 & 50 & 5 & 50 & 0 & 0 \\
\hline Levetiracetam 500mg tablet & 6 & 60 & 3 & 30 & 1 & 10 \\
\hline Levetiracetam $100 \mathrm{mg} / \mathrm{ml}$ syrup & 6 & 60 & 3 & 30 & 1 & 10 \\
\hline Levetiracetam $100 \mathrm{mg} / \mathrm{ml}$ injection & 7 & 70 & 2 & 20 & 1 & 10 \\
\hline Modafinil $100 \mathrm{mg}$ tablet & 2 & 20 & 6 & 60 & 2 & 20 \\
\hline Megestrol & 2 & 20 & 5 & 50 & 3 & 30 \\
\hline Escitalopram 10mg tablet & 6 & 60 & 4 & 40 & 0 & 0 \\
\hline Mertazapine $30 \mathrm{mg}$ tablet & 6 & 60 & 4 & 40 & 0 & 0 \\
\hline Baclofen $10 \mathrm{mg}$ tablet & 9 & 90 & 1 & 10 & 0 & 0 \\
\hline Furosemide $40 \mathrm{mg}$ tablet & 6 & 60 & 3 & 30 & 1 & 10 \\
\hline Furosemide $10 \mathrm{mg} / \mathrm{ml}$ & 7 & 70 & 2 & 20 & 1 & 10 \\
\hline $\begin{array}{l}\text { Bisphosphonate (Zoledronic acid, } \\
\text { Pamidronate) }\end{array}$ & 6 & 60 & 4 & 40 & 0 & 0 \\
\hline Vitamin D and Calcium & 4 & 40 & 3 & 30 & 3 & 30 \\
\hline
\end{tabular}

Table 2: National Palliative Care Medication List.

\begin{tabular}{|c|c|c|}
\hline Mandatory & Necessary & Optional \\
\hline Morphine $10 \mathrm{mg} / \mathrm{ml}$ injection & Hydromorphone $2 \mathrm{mg} / \mathrm{ml}$ injection & oxycodone $10 \mathrm{mg} / \mathrm{ml} \mathrm{injection}$ \\
\hline Morphine (IR) $10 \mathrm{mg}$ tablet & Hydromorphone (IR) $2 \mathrm{mg}$ tablet & Oxycodone $5 \mathrm{mg}$ immediate release tablet \\
\hline Morphine (IR) $10 \mathrm{mg} / 5 \mathrm{ml} \mathrm{syrup}$ & Hydromorphone (SR) $4 \mathrm{mg}$ tablet & Oxycodone $10 \mathrm{mg}$ sustained release tablet \\
\hline Morphine (SR) $10 \mathrm{mg}$ tablet & Methadone $5 \mathrm{mg}$ tablet & Buprenorphine $5 \mathrm{mcg} / \mathrm{hr}$ patch \\
\hline Morphine (SR) $30 \mathrm{mg}$ tablet & Fentanyl $12 \mathrm{mcg}$ patch & Buprenorphine $10 \mathrm{mcg} / \mathrm{hr}$ patch \\
\hline Morphine (SR) $60 \mathrm{mg}$ tablet & fentanyl $200 \mathrm{mcg}$ sublingual tablet & Methadone $2 \mathrm{mg} / \mathrm{ml}$ oral solution \\
\hline Fentanyl $100 \mathrm{mcg}$ injection & Ketamine $50 \mathrm{mgml}$ injection \\
\hline Fentanyl $500 \mathrm{mcg}$ injection & Diazepam $5 \mathrm{mg} / \mathrm{ml}$ Injection & Promethazine $10 \mathrm{mg}$ tablet \\
\hline Fentanyl $25 \mathrm{mcg}$ patch & Diazepam $5 \mathrm{mg}$ tablet & Promethazine $50 \mathrm{mg} / 2 \mathrm{ml} \mathrm{injection}$ \\
\hline Fentanyl $50 \mathrm{mcg}$ patch & Clonazepam $2.5 \mathrm{mg} / \mathrm{ml}$ oral drops & Movicol - POLYETHYLINE GLYCOL \\
\hline Fentanyl $100 \mathrm{mcg}$ patch & Haloperidol $5 \mathrm{mg}$ tablet & Phenytoin \\
\hline
\end{tabular}




\begin{tabular}{|c|c|c|}
\hline Fentanyl 100 mcg sublingual tablet & Amitriptyline 10 and $25 \mathrm{mg}$ tablet & Carbamazepine \\
\hline Codeine phosphate $30 \mathrm{mg}$ tablet & Ondansetron $2 \mathrm{mg} / \mathrm{ml}$ injection & Lamotrigine \\
\hline $\begin{array}{l}\text { Tylenol III (Acetaminophen 300mg \& codeine } \\
\text { 30mg) }\end{array}$ & Ondansetron $8 \mathrm{mg}$ tablet & Olanzapine \\
\hline Tramadol 100mg injection & Glycopyrronium $1 \mathrm{mg}$ tablet & Lidocane $5 \%$ patches \\
\hline Tramadol 50mg tablet & Hyoscine hydropromide $400 \mathrm{mcg} / 1 \mathrm{ml}$ injection & Methylnaltrexone \\
\hline Tramadol 100mg tablet & Sodium Valproate $200 \mathrm{mg} / 5 \mathrm{ml}$ elixir & Spironolactone \\
\hline Naloxone $0.4 \mathrm{mg} / \mathrm{ml}$ injection & Scopolamine $1.5 \mathrm{mg}$ patch & EMLA cream \\
\hline Acetaminophen 500mg tablet & Methylphenidate $20 \mathrm{mg}$ tablet & \\
\hline Ibuprofen $400 \mathrm{mg}$ tablet & Atropine $600 \mathrm{mcg} / \mathrm{ml}$ injection & \\
\hline Midazolam $15 \mathrm{mg} / 3 \mathrm{ml}$ injection & Diclofenac topical cream & \\
\hline \multicolumn{3}{|l|}{ Lorazepam $1 \mathrm{mg}$ tablet } \\
\hline \multicolumn{3}{|l|}{ Atropine eye drops $1 \%$} \\
\hline \multicolumn{3}{|l|}{ Benztropine $2 \mathrm{mg} / 2 \mathrm{ml}$ injection } \\
\hline \multicolumn{3}{|l|}{ Dexamethasone 8mg/2ml injection } \\
\hline \multicolumn{3}{|l|}{ Dexamethasone 8mg tablet } \\
\hline \multicolumn{3}{|l|}{ Prednisone $10 \mathrm{mg}$ tablet } \\
\hline \multicolumn{3}{|l|}{ Hyrdocortisone cream } \\
\hline \multicolumn{3}{|l|}{ Haloperidol $5 \mathrm{mg} / \mathrm{ml}$ injection } \\
\hline \multicolumn{3}{|l|}{ Octreotide $100 \mathrm{mcg} / \mathrm{ml}$ injection } \\
\hline \multicolumn{3}{|l|}{ Hyoscine butylbromide $20 \mathrm{mg} / 1 \mathrm{ml}$ injection } \\
\hline \multicolumn{3}{|l|}{ Glycopyrronium 200mcg/ml injection } \\
\hline \multicolumn{3}{|l|}{ Metoclopramide $10 \mathrm{mg} / 2 \mathrm{ml}$ injection } \\
\hline \multicolumn{3}{|l|}{ Metoclopramide $10 \mathrm{mg}$ tablet } \\
\hline \multicolumn{3}{|l|}{ Diphenhydramine $25 \mathrm{mg}$ tablet } \\
\hline \multicolumn{3}{|l|}{ Diphenhydramine $25 \mathrm{mg}$ injection } \\
\hline \multicolumn{3}{|l|}{ Bisacodyl 5mg tablet } \\
\hline \multicolumn{3}{|l|}{ Bisacodyl 10mg suppositories } \\
\hline \multicolumn{3}{|l|}{ Docusate sodium $100 \mathrm{mg}$ capsules } \\
\hline \multicolumn{3}{|l|}{ Senna 8mg tablet } \\
\hline \multicolumn{3}{|l|}{ Lactulose solution } \\
\hline \multicolumn{3}{|l|}{ Glycerine suppositories } \\
\hline \multicolumn{3}{|l|}{ Fleet enema } \\
\hline \multicolumn{3}{|l|}{ Loperamide $2 \mathrm{mg}$ capsules } \\
\hline \multicolumn{3}{|l|}{ Nystatin 100,000 units/ml oral liquid } \\
\hline Pregabalin 50mg and 150mg capsules & & \\
\hline Gabapentin $300 \mathrm{mg}$ and $800 \mathrm{mg}$ capsules & & \\
\hline Levetiracetam 500mg tablet & & \\
\hline Levetiracetam $100 \mathrm{mg} / \mathrm{ml}$ syrup & & \\
\hline Levetiracetam $100 \mathrm{mg} / \mathrm{ml}$ injection & & \\
\hline Modafinil 100mg tablet & & \\
\hline Megestrol & & \\
\hline Escitalopram 10mg tablet & & \\
\hline Mertazapine 30mg tablet & & \\
\hline Baclofen $10 \mathrm{mg}$ tablet & & \\
\hline Furosemide $40 \mathrm{mg}$ tablet & & \\
\hline Furosemide $10 \mathrm{mg} / \mathrm{ml}$ & & \\
\hline Bisphosphonate (Zoledronic acid, Pamidronate) & & \\
\hline Vitamin D and Calcium & & \\
\hline
\end{tabular}


The frequency was considered mandatory by $70 \%$ of the participants. The list of medications reported as "Mandatory" but less frequently (20\% of the participants), including modafinil $100 \mathrm{mg}$ tablets, megestrol, and fentanyl $500 \mathrm{mcg}$ injections, as shown in (Table 2). The "Necessary" medication list including the following: modafinil $100 \mathrm{mg}$ tablet (recommended by $60 \%$ of the participants), morphine (SR) $60 \mathrm{mg}$ tablet (50\%), megestrol (50\%), and prednisone $10 \mathrm{mg}$ tablet $(40 \%)$, as shown in (Table 2). For "Optional" medications, the percentage of participants who recommended fentanyl $500 \mathrm{mcg}$ injections was $50 \%$; hydrocortisone cream, 50\%; and atropine eye drops, $1 \%$ was $40 \%$.

\section{Discussion}

The primary objective of this project was to explore the degree of consensus among physicians involved in palliative care (PC) regarding appropriate pharmacological treatment for common symptoms of palliative patients with cancer and to thus develop a national medication list of essential medicines for PC based on expert opinion. Saudi Arabia is the largest state in Western Asia with an area of more than 2 million $\mathrm{km}^{2}$; Palliative care in Saudi Arabia is still in its nascent stages. Even after two decades, palliative care is not widely available across Saudi Arabia [15]. Meanwhile, the Ministry of Health (MOH) launched the Last Phase Initiative as part of the Transformation of Healthcare - Vision 2030. One of that initiative was to have national palliative care guideline to standardize the practice, where it was launched in 2018. Different palliative care physicians and nursing graduates from 16 different countries where the treat and dispense different medication due to different backgrounds practice. Also, the Medication Supply chain, drugs list in MOH wasn't include the different the majority of Narcotics medication. Even more, it didn't include the different form and strength of medication. Many patients receiving palliative care wish to remain at home for as long as possible. To help achieve this aim, they need rapid access to medicines to provide symptom relief. Such palliative care narcotics national medication list protocols support health professionals in the practice of handling and administering medicine to palliative care patients in tertiary, secondary hospitals or even living at home.

The research was attended by leading palliative consultants' specialists in the Kingdom of Saudi Arabia, with a high degree of agreement among experts. More than 60 drugs have been used in the study. Preference for prescription was divided into three categoriesmandatory, appropriate, and optional-based on the frequency of administration and the categories listed. "mandatory" medicines such as baclofen pills, loperamide, ibuprofen tablets, midazolam injections, Tylenol III and opioid injections, morphine injections, morphine (IR) syrup, and morphine (SR). This list will serve as a key for future decision making in clinical practice. We found a high level of consensus among the clinical PC experts about the EML and the "Mandatory," "Essential," and "Optional" Optional categories. More than 60 medications were reviewed and categorized by experts from different organizations. A recommendation based on a broad consensus-not only of the opinions resulting from this study, but also of the opinions supported by other existing documentationwill have great implications for changes in policy, education, and research, and may influence legislation and drug availability. Based on our findings, few medications, such as fentanyl and morphine midazolam, hyoscine butyl bromide, loperamide, haloperidol, hyoscine butyl bromide, docusate sodium, and acetaminophen, have been reported as frequently prescribed medications to PC patients, which corresponds with the WHO EML [16].

Drugs administered and identified in this study can be integrated into the WHO EML, which, in turn, may lead to a constructive improvement in municipal drug policy and provide the basis for a basic level of treatment for PC institutions. The main limitations are the lack of a pre-existing national PC medication list, flexibility within a defined framework, and various methods for different specialty practices. The number of doctors in our hospital, as well as whether or not they are effective members. Doctors' desire to distinguish their beliefs from their practices. If their experience differs from the national registry, even if they work outside of specialized PC environments. However, assessing the efficacy of an intervention over time can alleviate the burden of these limitations, especially in continuous improvement.

\section{Conclusion}

The medications prescribed and identified in this study should be integrated into the WHO EML, which may lead to a positive shift in local drug policies and serve as the foundation for minimum standards for PC institutions. Based on this consensus, other current recommendations, and taking into account all variations in local care traditions and drug availability. Our recommendations are that the medications used in the EML be made available in all settings caring for palliative patients, including those outside of specialist PC settings, in order to close the knowledge-practice gap. The PC guidelines listed in the previous list need to be revised. The central committee recommended that the Kingdom's top PC experts prepare a review of available evidence in support of the development of an EML for PC to ensure access to appropriate medicines for the pharmacological management of the most distressing symptoms of adult patients in KSA with life-threatening and life-limiting conditions.

\section{References}

1. Fliedner MC, Mitchell G, Bueche D, Mettler M, Schols JMGA, et al. (2019) Development and Use of the 'SENS'-Structure to Proactively Identify Care Needs in Early Palliative Care-An Innovative Approach. Healthcare $7(1): 32$.

2. (2020) Saudi Palliative Care National Clinical Guideline for Oncology.

3. Knaul FM, Bhadelia A, Atun R, Frenk J (2015) Achieving Effective Universal Health Coverage and Diagonal Approaches to Care For Chronic Illnesses. Health Aff (Millwood) 34(9): 1514-1522. 
4. (2011) WHO: Geneva, World Health Organization. Model.List of essential medicines. (17 ${ }^{\text {th }}$ Edn.)., WHO, Geneva, Switzerland.

5. Lindqvist O, Lundquist G, Dickman A, Bükki J, Lunder U, et al. (2013) Four essential drugs needed for quality care of the dying: a Delphi-study based international expert consensus opinion. J Palliat Med 16(1): 3843.

6. Merriman A, Harding R (2010) Pain control in the African context: the Ugandan introduction of affordable morphine to relieve suffering at the end of life. Philosophy, ethics, and humanities in medicine PEHM 5(10).

7. Good PD, Cavenagh JD, Currow DC, Woods DA, Tuffin PH, et al. (2006) What are the essential medications in pallative care? - a survey of Australian palliative care doctors. Aust Fam Physician 35(4): 261-264.

8. Nauck F, Ostgathe C, Klaschik E, Bausewein C, Fuchs M, et al. (2004) Working Group on the Core Documentation for Palliative Care Units in Germany. Drugs in palliative care: results from a representative survey in Germany. Palliat Med 18(2): 100-107.

9. Wirtz VJ, Hogerzeil HV, Gray AL, Bigdeli M, De Joncheere CP, et al. (2017) Essential medicines for universal health coverage. Lancet 389(10067): 403-476.

\section{ISSN: 2574-1241}

DOI: $10.26717 /$ BJSTR.2021.35.005778

Sami Ayed Alshammary. Biomed J Sci \& Tech Res

(C) (-) This work is licensed under Creative

Submission Link: https://biomedres.us/submit-manuscript.php
10. (1977) WHO. The selection of essential drugs: report of a WHO expert committee?

11. Essential Medicines List (EML) 2015 Commented Application Information to Be Included in an Application for Inclusion, Change or Deletion of a Medicine in the WHO Model List of Essential Medicines.

12. Bandameedi R, Mohammed S (2015) A Case Study on National List of Essential Medicines (NLEM) in India and WHO EML. Pharmaceutical Regulatory Affairs: Open Access 5(1): 1-8.

13. (2015) Understanding the Role and Use of Essential Medicines Lists.

14. Albert MA, Fretheim A, Maïga D (2007) Factors influencing the utilization of research findings by health policy-makers in a developing country: the selection of Mali's essential medicines. Health Res Policy Sys 5(2).

15. Alshammary S A, Duraisamy B, Albalawi Y, Savithiri Ratnapalan (2019) Development of Palliative and End of Life Care: The Current Situation in Saudi Arabia. Cureus 11(3): e4319.

16. (2019) WHO. World Health Organization Model List of Essential Medicines $21^{\text {st }}$ List 2019

$\begin{array}{ll}\text { BIOMEDICAL } & \text { Assets of Publishing with us } \\ \text { RESEARCHES } & \text { - Global archiving of articles } \\ & \text { - Immediate, unrestricted online access } \\ & \text { - }\end{array}$

